\title{
RESENHA: \\ QuANDo O Ponto SuRdo Não EnsuRdece E Algumas \\ Notas Psicanalíticas E Musicais
}

VIVÈS, J.-M. Variações psicanalíticas sobre a voz e a pulsão invocante. Tradução: Vera Avellar Ribeiro. Rio de Janeiro: Contra Capa, 2018. 164 p.

\section{Lucas Emmanoel Cardoso de Oliveira1}

Este trabalho objetiva apresentar e fazer um convite à leitura do livro "Variações psicanalíticas sobre a voz e a pulsão invocante" de Jean-Michel Vivès, lançado no Brasil em 2019. Este livro é composto por uma coletânea de textos, diferentes e não dicotomizados um do outro, produzidos no período de 2014 a 2017, e buscaram atender aos questionamentos suscitados no primeiro livro publicado no Brasil, em 2012 2. Assim, decidimos mencionar e refletir alguns temas - de tantos tão interessantes - que perpassam as suas pesquisas, dando destaque à noção de "ponto surdo" cunhada pelo autor.

De qual voz se trata na psicanálise? Não é a voz tornada via para a comunicação, não é aquela que com a sua consistência imaginária do som passa pelos ouvidos, mas é a que ecoa internamente e compulsoriamente exigindo o gozo ao sujeito. Esta voz foi elevada por Lacan a estatuto de objeto pulsional, chamando-a de objeto $a$, objeto voz, o qual se pode conceber como um conceito operativo referido à experiência subjetiva de ser acometido pelo indeterminado da pulsão invocante. Assim, o objeto voz manifesta o não-sentido do real, e se faz reconhecer no encadeamento com o imaginário - sentido - e o simbólico - duplo sentido. De modo que a voz com a qual falamos e é escutada, que é apreendida na dimensão imaginária e simbólica, se põe a tentar fazer calar o que se chama de objeto voz (MILLER,

1 Psicanalista (Corpo Freudiano-RJ), mestre em psicanálise: clínica e cultura (PUC-RJ), psicólogo (PUC-GO) e psicólogo educacional/psicanalista da Universidade Federal de Santa Catarina - Campus Curitibanos.

2 VIVĖS, J.-M. A voz na clínica psicanalítica. Rio de Janeiro: Contra Capa, 2012.

Psicanálise \& Barroco em revista | v.17, n. 3 | dezembro de 2019 
1989/2013). Percebo que é a partir desta perspectiva que Vivés faz as suas múltiplas interações entre o objeto voz e outros saberes.

Em Para introduzir a questão do ponto surdo, Vivès (2018) retoma e expande o que vem desenvolvendo sobre a noção de ponto surdo indicativo de um testemunho do estabelecimento do recalque originário 3. Assim, este lugar intra-psíquico faz referência ao processo de perda, esquecimento e ensurdecimento em relação à voz do Outro primordial, o que é condição para a produção do sujeito do inconsciente que fala sem saber o que diz e com uma voz - mais que narcisicamente própria - singular diante das múltiplas vozes que the constitui. No entanto, concomitante a esse processo e subjacente a ele, pulsa inadvertidamente o gozo com a voz do Outro, que foi inesquecível e por isso não ensurdecida. De modo que o sujeito assume (Bejahung) e rejeita (Ausstossung) a voz do Outro. Desse modo, Vivès (2018) indica que o ponto surdo, tão hipotético como o recalque originário, parece ser necessário para o entendimento da subjetivação relacionado ao circuito da pulsão invocante.

E neste livro, Vivès (2018) apresenta um apontamento novo em relação à produção de 2012: o fato de que o ponto surdo não se dá de uma vez por todas. 0 autor indica que: "os pacientes neuróticos podem, eventualmente, ver-se confrontados com o desaparecimento momentâneo desse ponto de ensurdecimento, ficando então expostos às vozes que, até então, mantiveram à distancia" (p.24). Ou seja, no sujeito neurótico, o ponto surdo pode não se ensurdecer diante da voz primordial, vivendo algo “"comparável” mas não "idêntico” a uma "alucinação”"(DIDIER-WEILL,1997, p.137); o que reafirma a impossibilidade de garantia de surdez na neurose 4, aproximando esta estrutura da psicose e do autismo nas quais o ponto surdo não se encontra constituído. Desse modo, o ponto surdo deve ser "atualizado em um movimento espiral que acompanha o próprio processo de humanização, sobretudo cada vez que o sujeito for nadificado e tornado objeto pela vociferação do Outro" (OLIVEIRA \& VIEIRA, 2019, p.163). Por outro lado, isso mostra que, em certas condições, seria possível efetuar nos sujeitos psicóticos e autistas, "um "enxerto" do

\footnotetext{
${ }_{3} \mathrm{O}$ autor indica que esta formulação de Freud tem como base os seguintes textos: "Projeto para uma psicologia científica" (1895), carta 112 enviada a Wilhelm Fliess em 6 de Dezembro de 1896 (FREUD, 1896), "O recalque" (1915), "O inconsciente" (1915) e "A negação" (1925).

4 Sobre isso, ver: OLIVEIRA, L.E.C. \& VIEIRA, M.A. Sobre o esquecimento inesquecível da voz do Outro: supereu, objeto voz e música. In: Revista Affectio Societatis, Vol. 16, N. 30, enero-junio de 2019. Recuperado em: https://aprendeenlinea.udea.edu.co/revistas/index.php/affectiosocietatis/article/view/328798.
} 
ponto surdo" (VIVĖS, 2018, p.24). Este entendimento, o mito dos argonautas, o escrito autobiográfico de Schreber e a sua própria experiência são alguns dos elementos que permitem ao autor propor a música, capturada em uma relação transferencial, como uma possibilidade de fazer suplência à não constituição do ponto surdo, operando como um "lugar-tenente" (VIVÈS, 2018, p.27).

E quanto à utilização da música na clínica psicanalítica, à revelia de um furor curandis musicoterapêutico, Vivès (2018, p.93) é categórico: "não existe musicoterapia". Reconhece os trabalhos que têm sido realizados em torno da relação entre afeto e a escuta musical, mas delimita o seu campo de investigação: estabelecer como a música poderia contribuir para manter o objeto voz à distância, em uma experiência sempre envolvida pela transferência.

No texto Sobre a improvisação materna, Vivès (2018) ressalta que a improvisação, tanto musical quanto linguageira, não é desprovida de saber. O músico improvisa a partir dos elementos musicais internalizados, e a mãe ou quem ocupa a "função improvisante" 5 o fará baseada na relação que mantém com a linguagem e a lei, imprimindo nesse gesto, o seu posicionamento subjetivo. E nesse processo de improvisação primordial, o autor destaca a fundamental parceria em duo na constituição do sujeito e do Outro, e não supõe que "algo estaria desde sempre escrito na criança" (p.33), conjecturando que seria mais apropriado pensar que "a mãe lê na criança algo que não está escrito nela, mas nesse mesmo ato de leitura dá à criança a oportunidade de inscrever-se nisso" (p.33). Sobre isso, e a partir da apreensão dos trabalhos de Cabassu-Crespin (2007), na improvisação o adulto seria para com o bebê "um sujeito suposto saber que há (verá) sujeito" (VIVĖS, 2018, p.38), remetendo este entendimento às contribuições de Didier-Weill.

E uma outra novidade neste livro, é que o autor propõe os três tempos da improvisação materna: $1^{\circ}$ tempo: suposição, como um ato de fé de que no bebê advirá um sujeito; $2^{\circ}$ tempo: onde o bebê, depois de ter se deixado engodar pelo gozo da

5 LAZNIK, M-C. Vers la parole: trois enfants autistes em psychanalyse. Paris: Denoel, 1995.

. La prosodie avec lês bébés à risque d'autisme: clinique et recherche. In: JOLY, F.; LAZNIK, M.-C. \& TOUATI, B. (dir.). Language, voix et aprole dans l'autism, 2007. , et all. Les interactions sonores entre les bébés devenus autistes et leurs parents. In: CASTARÈDE, M.-F. \& KONOPCZYNSKI, G. (dir.). Au commencement était la voix. Toulouse: Erès, 2005. 
voz do Outro, constitui um duo com a mãe; 3ํtempo: endereçamento da mãe ao bebê, especialmente, sob forma de questionamento. E somado a isso, o autor apresenta dois tipos de silêncios integrados aos tempos lógicos da improvisação: um silêncio inicial - como naquele em que o maestro levanta a batuta no começo do concerto como aposta na emergência de um sujeito, e um segundo silêncio que encadeia uma vocalização a outra, estruturando a fala.

E o que torna uma voz tão singular? Neste texto, Vivès (2018) desenvolve esta preciosa questão para a clínica psicanalítica. E nesse livro, ele apresenta reflexões sobre o timbre da voz, o que tinha sido apenas indicado em 2012. Diferente dos parâmetros do som: altura, intensidade, duração, nos quais tem uma medida precisa, o timbre é refratário a uma medida concreta, restando-Ihe apenas significantes que o denotam. Assim, Vivès apreenderá o timbre psicanaliticamente como uma manifestação da "negativização do simbólico" (p.46). E é justamente esse timbre emitido pela voz do Outro que movimentará a pulsão invocante, que orientará a busca desejante do proto-sujeito, o qual precisará, no entanto, dizer "sim" e "não" àquele timbre.

Uma outra questão instigante que Vivès (2018) investiga é: o que ouvimos quando nos ouvimos? Esta experiência de inquietante estranheza do ordinário da vida, comumente não refletida, se desdobra na pergunta: "O que preferiríamos não ouvir quando nos ouvimos?" (p.49)6. A explicação fisiológica é mencionada apenas para reafirmar o fato de que a significação não aplaca o mal estar vivido pelo sujeito ao escutar a sua própria voz. Vivès parte da reflexão sobre a constituição do mundo e do eu, seguindo em uma sofisticada elaboração para encontrar respostas a estas questões.

Em $O$ ateliê interior de Theodor Reik ou a arte musical da psicanálise, Vivès (2018) vai recuperar importantes contribuições de Theodor Reik, sobre sentimento de culpa, supereu e música, e vai investigar, especialmente a obra: $A$ melodia obsedante: experiências psicanalíticas na vida e na música (REIK, 1953).

\footnotetext{
6 Como um testemunho dessa experiência de se escutar, sugiro o filme Marguerite (2016), do diretor Xavier Giannoli, baseado na história real de Florence Foster, a qual tinha o sonho de se tornar uma grande cantora, o que era "reafirmado" pelo seu meio. Contudo, em uma certa cena, quando Florence se depara com o registro da sua própria voz, com o imaginário sonoro que não reflete o que ela fantasiava, não reassegurando aquilo que Ihe conferia existência, a angústia comparece retirando-lhe a consistência que até então foi construída. Em 1944, no Carnegie Hall, foi registrada uma apresentação de Florence Foster: https://www.youtube.com/watch?v=V6ubiUlxbWE.
} 
Parte da experiência de Reik em que este é obsedado, apoderado, por um dos temas da sinfonia de Mahler após ter sido tomado pela notícia do falecimento de Karl Abraham, que foi seu analista muito admirado e, posteriormente, tornou-se seu amigo. Theodor Reik empreende uma investigação sobre o determinismo inconsciente dessa experiência de ser obsedado pela música; o que para Vivès (2018) revela um saber fecundo para a clínica psicanalítica e, também, para as pesquisas sobre a relação entre psicanálise e música.

Distante de uma tentativa de relacionar a sua experiência com a letra da música - já que a parte da peça musical que o arrebatou é justamente quando o coro canta os versos da ode Ressureição, do poeta alemão Friedrich Gottlieg Klopstock (17241803) - Reik parte da perspectiva de que a sua experiência angustiante se relacionava com a melodia, e segue a sua auto-análise, apresentando corajosamente o seu processo de criação no seu "ateliê interior". Como compreender analiticamente o fenômeno da melodia obsedante? Para responder a esta questão, Vivès (2018) se fundamentará em uma consistente pesquisa, desenvolvendo durante este texto uma articulação sensível e sofisticada entre significantes, em uma construção psicanalítica e artística surpreendente, que o é justamente por revelar a reafirmação do que nos é constitutivo e nos une: o assassinato do pai primordial. Somos convocados a dar lugar a este assassinato e a bem dizê-lo, sob o risco de sermos invadidos e insultados pelo supereu, referido ao pai sem rédias que não para de morrer.

No texto $A$ voz de pai para filho: uma leitura das vozes do supereu à luz da obra de Theodor Reik, Vivès reapresenta suas pesquisas já publicadas em 2012 sobre as vozes do supereu e retoma as investigações clínicas e antropológicas de Theodor Reik sobre o chofar, expandindo mais ainda as suas reflexões. E partindo da hipótese de que o som do chofar trataria os efeitos das vozes do supereu, o autor faz um instigante questionamento: "Como se pode compreender que o psicanalista, por meio de sua intervenção, está na posição de chofar para o analisando?" (VIVÈS, 2018, p.90). Para responder a esta questão e a outras referidas às vozes do supereu que causam devastação e fascínio, determinando o gozo, Vivès destaca a importância do desejo como condição para o sujeito "endereçar, ser endereçado e fazer-se endereçar" (VIVÈS, 2018, p.92), de modo a encontrar um lugar para si no concerto do mundo. 
Em Música e psicose, Vivès fará o movimento investigativo de escutar a psicose para se pensar a neurose, ou seja, reconsiderar a neurose do ponto de vista da psicose e não o contrário como tradicionalmente o é feito sob o risco de se instituir normatividades. O psicanalista vai desenvolver uma noção muito importante para os processos psíquicos que é o de "espaço psíquico íntimo". Ressalta que o "sujeito psicótico é confrontado com um Outro "pan-fônico"” (VIVÈS, 2018, p.98) que invade e devasta o sujeito com as suas vozes de injúria e o seu olhar persecutório, impedindo a constituição de um lugar psíquico no qual se possa produzir fronteiras entre o eu e o Outro. Por isso a importância da formação do delírio para o psicótico, como uma possibilidade de ligar os pedaços do destilhaçamento psíquico. Já na neurose, se produz fronteiras, defesas, que autorizam a constituição desse espaço psíquico que se põe a barrar o Outro. Assim, Vivès (2018, p.97) questiona: seria possível postular a constituição de um "enxerto de intimidade" no psicótico? A mediação musical será privilegiada para responder a esta questão. E apresenta, belamente, a experiência entre o célebre castrato Farinelli e o melancólico rei da Espanha Felipe V., como uma invocação musical a ser retomada pelo psicanalista!

E conclui o livro com o texto Da impossível cessão do objeto voz a um possível investimento da voz: o passe ressoante do autista, Vivès (2018) abre sua discussão com um entendimento determinante: "O autista interroga o homem sobre sua relação fundamental com a linguagem" (p.101). Por dentro desse entendimento, o autor apresenta que a enunciação, como presentificação do "peso do sujeito", é recusada pelo autista, ao contrário da voz artificial - gravados, fixado sobre um suporte, fora do corpo; da voz maquinal - inteiramente criada, desprovida de sujeito; fraseados musicais, sem palavras, sem o sentido; ou ainda da voz do outro, quando esta é monótona. Estas são formas que permitiriam o apagamento da "dimensão subjetiva da enunciação com o desaparecimento do timbre (total ou parcial)" (VIVÈS, 2018, p.110). E destacando o manejo da presença possível do "peso do sujeito", Vivès alerta para o comparecimento excessivo da enunciação que faria o autista se distanciar e para o risco da indiferença que tornaria o operador clínico ineficaz, propondo assim, a "clínica do detalhe" (p.111), referido ao que se dá no caso a caso.

Vivès dedica este livro a Alain Didier-Weill que não está na materialidade da vida desde novembro de 2018 , deixando uma obra e uma transmissão inestimável 
para a psicanálise. Os efeitos do seu espírito musical se encontram de modo brilhante neste livro.

E quanto ao sucesso da noção de "ponto surdo" no Brasil, além desse entendimento ter uma consistência lógica que aprofunda a investigação da relação do sujeito com a pulsão invocante, arrisco-me a conjecturar que esta resposta do Brasil àquela noção se dá também pelo fato de que o brasileiro desde a sua fundação histórica e subjetiva precisou inventar formas, especialmente artísticas, para reafirmar em uma forma espiral o seu ponto surdo frente ao insulto paralisante do supereu aderente ao totalitarismo colonizador, de modo que podemos testemunhar que a produção de um corpo subversivo - invocado pela arte - como repúdio ao domínio social tem sido a nossa garantia de sobrevivência vital e psíquica.

E como uma mensagem de náufrago lançada ao mar, Vivès afirma que seus textos "podem ser lidos como um desdobramento e uma tentativa de explicitação do que permanece para mim, ainda e sempre, uma noção em construção" (p.10). A garrafa de náufrago chegou ao litoral brasileiro, tem chegado ao Brasil de dentro, carregando o seu endereçamento invocante como letra que impele aos novos encontros e à escrita inconclusa, como testemunhos éticos da psicanálise.

Assim como o autor que faz do seu livro uma invocação, com este texto o meu gesto é de re(invocação) para que os leitores apreciem mais essa preciosidade de Jean-Michel Vivès. 


\section{REFERÊNCIAS}

DIDIER-WEILL, A. Os três tempos da lei: O mandamento siderante, a injunção do supereu e a invocação musical. Rio de Janeiro, Brasil: Jorge Zahar, 1997.

CABASSUS-CRESPIN, G. L`histoire de Bob... ou l’émergence du sujet dans son arrimage au discours de l'Autre. In: JOLY, F.; LAZNIK, M.-C. \& TOUATI, B. (dir.). Langage, voix et parole dans l'autism. Paris: Presses universitaires de France.

JENKINS, F. F. Florence Foster Jenkins - Queen of the Night by Mozart. Disponível em: https://www.youtube.com/watch?v=V6ubiUIxbWE. Acesso em: nov.2019.

LAZNIK, M-C. Vers la parole: trois enfants autistes em psychanalyse. Paris: Denoel, 1995. . La prosodie avec lês bébés à risque d`autisme: clinique et recherche. In: JOLY, F.; LAZNIK, M.-C. \& TOUATI, B. (dir.). Language, voix et aprole dans l'autism, 2007. , et all. Les interactions sonores entre les bébés devenus autistes et leurs parents. In: CASTARÈDE, M.-F. \& KONOPCZYNSKI, G. (dir.). Au commencement était la voix. Toulouse: Erès, 2005.

MILLER, J-A. (1989/2013). Lacan e a voz. Opção Lacaniana online nova série, 4(11), 1-13. Recuperado em: http://www.opcaolacaniana.com.br/pdf/ numero_11/voz.pdf.

OLIVEIRA, L.E.C. \& VIEIRA, M.A. Sobre o esquecimento inesquecível da voz do Outro: supereu, objeto voz e música. In: Revista Affectio Societatis, v. 16, n. 30, p.144-173, enerojunio 2019. Disponível em:

https://aprendeenlinea.udea.edu.co/revistas/index.php/affectiosocietatis/article/view/328798. Acesso em: out.2019, 17h00min.

VIVÈS, J.-M. A voz na clínica psicanalítica. Rio de Janeiro: Contra Capa, 2012. . Variações psicanalíticas sobre a voz e a pulsão invocante. Tradução: Vera Avellar Ribeiro. Rio de Janeiro: Contra Capa; Corpo Freudiano Seção Rio de Janeiro, 2018. 
Quando O Ponto SuRdo NÃo EnSURdeCE E Algumas Notas PSicanalíticas E MUSicaIS

RECEBIDO EM 25-10-2019

APROVADO EM 25-11-2019

(C) 2019 Psicanálise \& Barroco em revista

http://www.seer.unirio.br/index.php/psicanalise-barroco/index

revista@psicanaliseebarroco.pro.br

Programa de Pós-Graduação em Memória Social — UNIRIO

Memória, Subjetividade e Criação

www.memoriasocial.pro.br/proposta-area.php 